\title{
The Human Early-Life Exposome (HELIX): Project Rationale and Design
}

\author{
Martine Vrijheid, ${ }^{1,2,3}$ Rémy Slama, ${ }^{4}$ Oliver Robinson, ${ }^{1,2,3}$ Leda Chatzi, ${ }^{5}$ Muireann Coen, ${ }^{6}$ Peter van den Hazel, ${ }^{7}$ \\ Cathrine Thomsen, ${ }^{8}$ John Wright, ${ }^{9}$ Toby J. Athersuch, ${ }^{6}$ Narcis Avellana, ${ }^{10}$ Xavier Basagaña, ${ }^{1,2,3}$ Celine Brochot, ${ }^{11}$ \\ Luca Bucchini, ${ }^{12}$ Mariona Bustamante, 1,3,13,14 Angel Carracedo, 15,16 Maribel Casas, 1,2,3 Xavier Estivill, 2,3,13,14 \\ Lesley Fairley, ${ }^{9}$ Diana van Gent, ${ }^{1,2,3}$ Juan R. Gonzalez, ${ }^{1,2,3}$ Berit Granum, ${ }^{8}$ Regina Gražulevičienè, ${ }^{17}$ \\ Kristine B. Gutzkow, ${ }^{8}$ Jordi Julvez, ${ }^{1,2,3,14}$ Hector C. Keun, ${ }^{6}$ Manolis Kogevinas, ${ }^{1,2,3,14}$ Rosemary R.C. McEachan, ${ }^{9}$ \\ Helle Margrete Meltzer, ${ }^{8}$ Eduard Sabidó, ${ }^{13}$ Per E. Schwarze, ${ }^{8}$ Valérie Siroux, ${ }^{4}$ Jordi Sunyer, $, 2,3,14$ \\ Elizabeth J. Want, ${ }^{6}$ Florence Zeman, ${ }^{11}$ and Mark J. Nieuwenhuijsen ${ }^{1,2,3}$
}

${ }^{1}$ Centre for Research in Environmental Epidemiology (CREAL), Barcelona, Spain; ${ }^{2}$ Universitat Pompeu Fabra (UPF), Barcelona, Spain; ${ }^{3}$ CIBER Epidemiología y Salud Pública (CIBERESP), Barcelona, Spain; ${ }^{4}$ Institut National de la Santé et de la Recherche Médicale (INSERM), Institut Albert Bonniot (U823), Grenoble, France; ${ }^{5}$ University of Crete (UOC), Heraklion, Crete, Greece; ${ }^{6}$ Imperial College London (ICL), London, United Kingdom; ${ }^{7}$ Veiligheids- en Gezondheidsregio Gelderland Midden (VGGM), Arnhem, the Netherlands; ${ }^{8}$ Norwegian Institute of Public Health (NIPH), Oslo, Norway; ${ }^{9}$ Bradford Institute for Health Research, Bradford Teaching Hospitals NHS Foundation Trust (BTHFT), Bradford, United Kingdom; ${ }^{10}$ Sensing \& Control Systems S.L. (S\&C), Barcelona, Spain; ${ }^{11}$ Institut National de I'Environnement Industriel et des Risques (INERIS), Unit of Models for Ecotoxicology and Toxicology, Paris, France; ${ }^{2}$ Hylobates Consulting S.R.L. (HYLO), Rome, Italy; ${ }^{13}$ Centre for Genomic Regulation (CRG), Barcelona, Spain; ${ }^{14}$ IMIM Hospital del Mar Research Insititute, Barcelona, Spain; ${ }^{15}$ Grupo de Medicina Xenomica, Fundación Pública Galega de Medicina Xeómica (SERGAS), CIBERERCEGEN, Universidade de Santiago de Compostela, Santiago de Compostela, Spain; ${ }^{16}$ Center of Excellence in Genomic Medicine Research, King Abdulaziz University, Jeddah, Kingdom of Saudi Arabia; ${ }^{17}$ Vytauto Didziojo Universitetas (VDU), Kaunus, Lithuania

BACKGROUND: Developmental periods in early life may be particularly vulnerable to impacts of environmental exposures. Human research on this topic has generally focused on single exposurehealth effect relationships. The "exposome" concept encompasses the totality of exposures from conception onward, complementing the genome.

ОвJестіVEs: The Human Early-Life Exposome (HELIX) project is a new collaborative research project that aims to implement novel exposure assessment and biomarker methods to characterize early-life exposure to multiple environmental factors and associate these with omics biomarkers and child health outcomes, thus characterizing the "early-life exposome." Here we describe the general design of the project.

METHODS: In six existing birth cohort studies in Europe, HELIX will estimate prenatal and postnatal exposure to a broad range of chemical and physical exposures. Exposure models will be developed for the full cohorts totaling 32,000 mother-child pairs, and biomarkers will be measured in a subset of 1,200 mother-child pairs. Nested repeat-sampling panel studies $(n=150)$ will collect data on biomarker variability, use smartphones to assess mobility and physical activity, and perform personal exposure monitoring. Omics techniques will determine molecular profiles (metabolome, proteome, transcriptome, epigenome) associated with exposures. Statistical methods for multiple exposures will provide exposure-response estimates for fetal and child growth, obesity, neurodevelopment, and respiratory outcomes. A health impact assessment exercise will evaluate risks and benefits of combined exposures.

Conclusions: HELIX is one of the first attempts to describe the early-life exposome of European populations and unravel its relation to omics markers and health in childhood. As proof of concept, it will form an important first step toward the life-course exposome.

Citation: Vrijheid M, Slama R, Robinson O, Chatzi L, Coen M, van den Hazel P, Thomsen C, Wright J, Athersuch TJ, Avellana N, Basagańa X, Brochot C, Bucchini L, Bustamante M, Carracedo A, Casas M, Estivill X, Fairley L, van Gent D, Gonzalez JR, Granum B, Gražulevičienè R, Gutzkow KB, Julvez J, Keun HC, Kogevinas M, McEachan RR, Meltzer HM, Sabidó E, Schwarze PE, Siroux V, Sunyer J, Want EJ, Zeman F, Nieuwenhuijsen MJ. 2014. The Human Early-Life Exposome (HELIX): project rationale and design. Environ Health Perspect 122:535-544; http://dx.doi.org/10.1289/ehp.1307204

\section{Introduction}

Environmental hazards such as ambient air pollution, environmental tobacco smoke (ETS), noise, pesticides, and radiation may lead to serious, chronic pathologies. The fetus and infant are particularly vulnerable to such potential hazards (Barouki et al. 2012; Gluckman and Hanson 2004; Hines et al. 2010). Environmental exposures-preconceptionally, in utero, and during early life-may permanently change the body's structure, physiology, and metabolism (Gluckman and Hanson 2004). Such changes can promote disease long after of how simultaneous environmental risk factors interact among themselves, with individual characteristics (e.g., genetics), and with epigenetics, can help elucidate their causes (Bousquet et al. 2011; Gallagher et al. 2011; Trasande et al. 2009; Van den Bergh 2011). Up to now, the field of environment and child health has almost uniquely focused on single exposure-health effect relationships; there is no global view of how various types of exposures co-exist and jointly affect health.

The exposome. The "exposome" concept was first proposed by Wild (2005) to encompass the totality of human environmental (i.e., nongenetic) exposures from conception onward, complementing the genome; it was developed "to draw attention to the critical need for more complete environmental exposure data in epidemiological studies" (Wild 2012). In this concept, the exposome contains several overlapping domains of nongenetic factors contributing to disease risk, including a general external domain (social, societal, urban environment, climate factors), a specific external domain (specific contaminants, lifestyle factors, tobacco, occupation),

Address correspondence to M. Vrijheid, Center for Research in Environmental Epidemiology (CREAL), Parc de Recerca Biomèdica de Barcelona-PRBB, C. Doctor Aiguader, 88, 08003 Barcelona, Spain. Telephone: 34932147 346. E-mail: mvrijheid@ creal.cat

Supplemental Material is available online (http:// dx.doi.org/10.1289/ehp.1307204).

This research received funding from the European Community's Seventh Framework Programme (FP7/2007-2013) under grant agreement 308333the HELIX project.

N.A. is employed by Sensing \& Control Systems SL, Igualada, Spain. L.B. is employed by Hylobates Consulting S.R.L., Rome, Italy. The authors declare they have no actual or potential competing financial interests.

Received: 11 June 2013; Accepted: 6 March 2014; Advance Publication: 7 March 2014; Final Publication: 1 June 2014. 
and an internal environment (metabolism, gut microflora, inflammation, oxidative stress) (Wild 2012). The exposome calls for improvement of often uncertain exposure data, for integration of data on biological mechanisms, and for a more holistic exposure approach in epidemiological studies. Furthermore, it has been proposed that the exposome may serve an important purpose in characterizing not only the complex mixtures of already identified exposures but also, through its untargeted approach and the use of highthroughput "omics" techniques, relevant exposures that have thus far remained unidentified (Rappaport 2011; Rappaport and Smith 2010). There are large challenges in developing the exposome concept into a workable

1. Measuring the external exposome

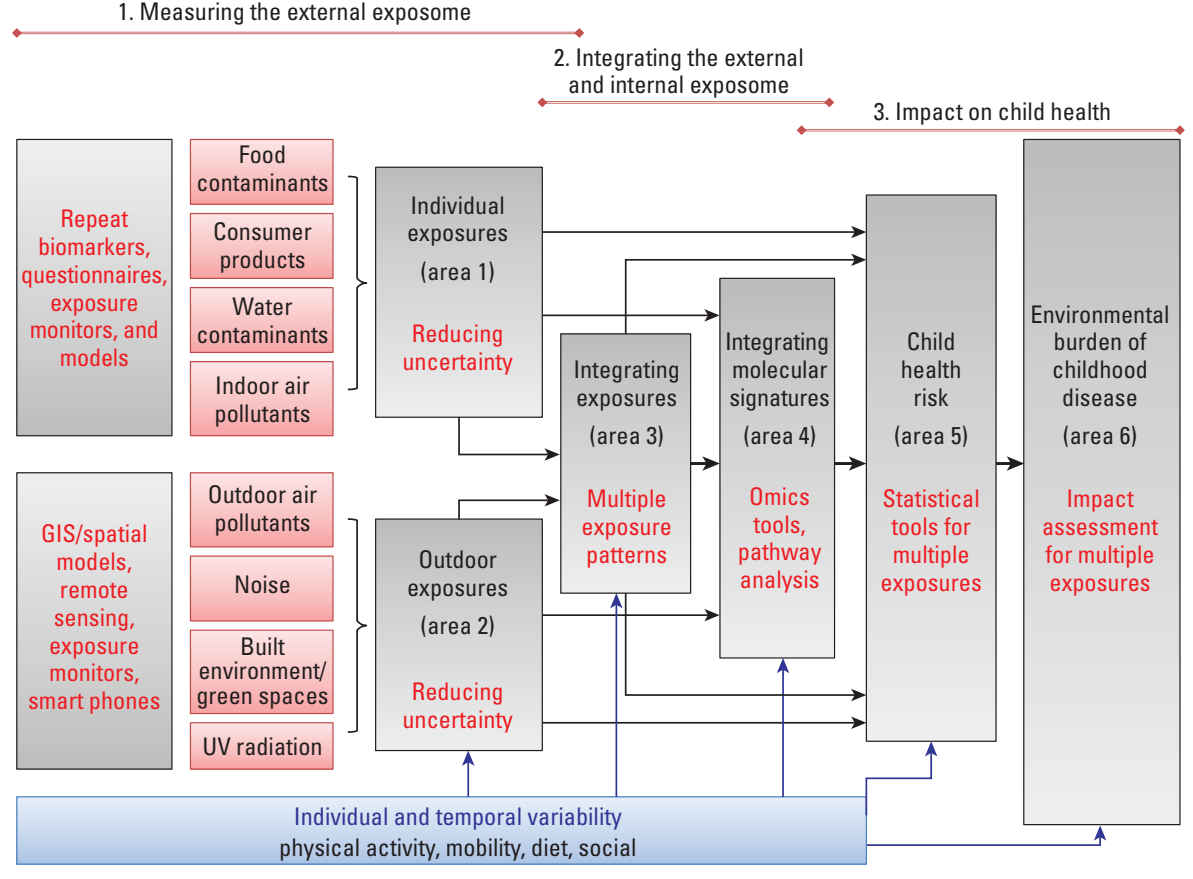

Figure 1. HELIX conceptual framework and interactions between research areas.

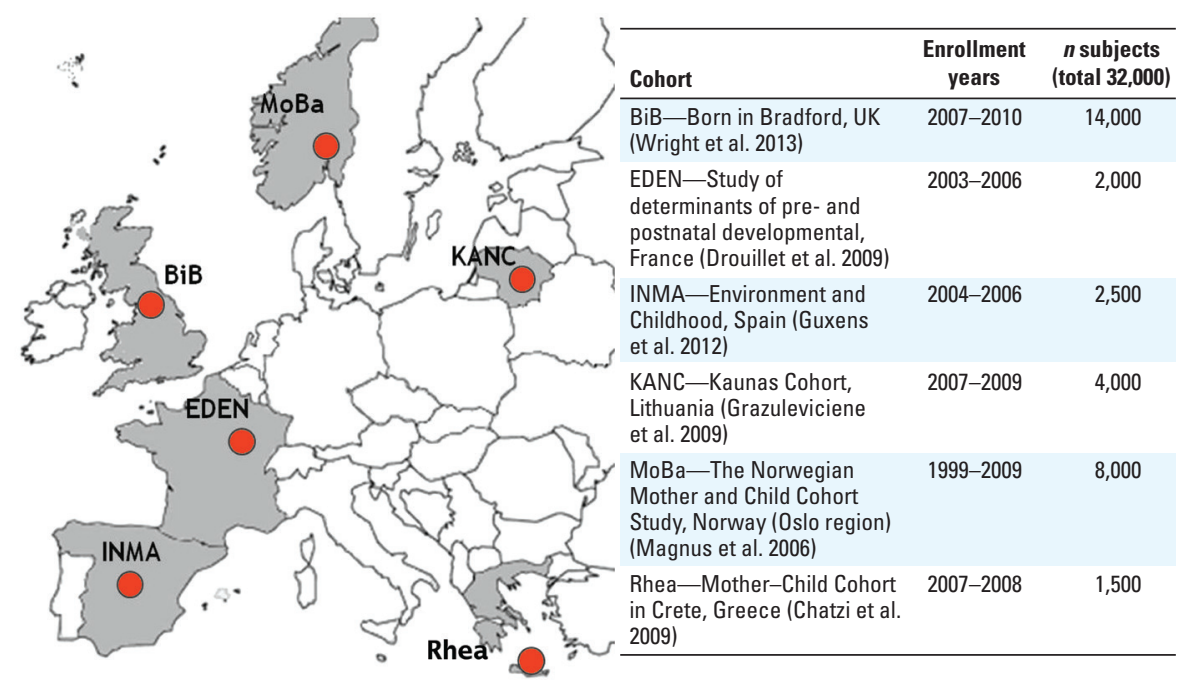

Figure 2. Participating birth cohorts. approach, including the consideration of multiple, longitudinal time periods of interest and of temporal variability, the acknowledgement of exposure uncertainty in an exposome study, the integration of omics data, and the development of powerful statistical techniques to analyze the associations between exposome data and adverse health end points.

The HELIX (Human Early-Life Exposome) project has as its general aim to implement tools and methods (biomarkers, omics-based approaches, remote sensing and GIS-based spatial methods, personal exposure devices, statistical tools for combined exposures, and burden of disease methodologies), to characterize early-life exposure to a wide range of chemical and physical environmental factors and associate these with data on major child health outcomes (growth and obesity, neurodevelopment, respiratory health), thus developing an "early-life exposome" approach. The project takes pregnancy and childhood periods ("early life") as the starting point for developing the life-course exposome. In this review we describe the general design of HELIX and its main challenges. In this manner, we aim to illustrate how the exposome concept may be implemented in a feasible epidemiological study design.

\section{Project Concept, Objectives, and Study Populations}

HELIX will develop the early-life exposome approach and database in three overlapping steps containing six research areas (Figure 1). A first step will measure the external exposome exposure estimates for a broad range of chemical and physical exposures; a second step will measure the internal exposome (molecular signatures) and integrate the multiple dimensions of the exposome (multiple exposures, multiple time points, individual variability); and a third step will develop the tools and methods to evaluate the exposome's impact on child health (Figure 1). The project is based in six existing population-based birth cohort studies in Europe (Figure 2). Objectives are the following:

Step 1: Measuring the external exposome:

- To obtain estimates of exposure to persistent and nonpersistent pollutants in food, consumer products, water, and indoor air, during pregnancy and in childhood.

- To obtain estimates of chemical and physical exposures in the outdoor environment during pregnancy and in childhood: ambient air pollution, ambient noise, ultraviolet (UV) radiation, temperature, and built environment/green space.

Step 2: Integrating the external and internal exposome:

- To define multiple exposure patterns in the individual and outdoor environment, describe their predictors, and describe uncertainties and variability in the exposures assessed.

- To measure molecular signatures associated with environmental exposures through analysis of profiles of metabolites, proteins, transcripts, and DNA methylation in biological samples from the children in the cohorts. Biological pathway analyses will be used to inform analyses of the relationship between multiple exposures and child health.

Step 3: Impact of the early-life exposome on child health:

- To develop a novel multistep statistical approach for the analysis of the association of patterns of multiple and combined exposures and child health outcomes, using agnostic environment-wide association 
study (EWAS) analysis, structural equation modeling (SEM), and Bayesian profile regression.

- To provide exposure-response estimates for the association of multiple and combined exposures with child health, focusing on fetal and childhood growth and obesity, neurodevelopment, and respiratory health.

- To estimate the burden of common childhood diseases that may be attributed to multiple environmental exposures in Europe.

- To strengthen the knowledge base for European policy in the area of child and environmental health by engaging with, and effectively disseminating HELIX knowledge to stakeholders including those responsible for risk management and mitigation and prevention strategies.

The birth cohorts. Six existing longitudinal population-based birth cohort studies in Europe form the basis of the project: $\mathrm{BiB}$ (Born in Bradford; United Kingdom) (Wright et al. 2013), EDEN (Étude des Déterminants pré et postnatals du développement et de la santé de l'ENfant; France) (Drouillet et al. 2009), INMA (INfancia y Medio Ambiente; Spain) (Guxens et al. 2012), KANC (Kaunus Cohort; Lithuania) (Grazuleviciene et al. 2009), MoBa (Norwegian Mother and Child Cohort Study; Norway) (Magnus et al. 2006), and Rhea (Greece) (Chatzi et al. 2009) (Figure 2). The cohorts were selected because $a$ ) they each have a large set of existing longitudinal data from early pregnancy through childhood; $b$ ) they can implement new follow-up examinations of the children at similar ages (6-9 years), old enough for accurate measurement of the phenotypes of interest for HELIX; and $c$ ) they can integrate new questionnaires, biosampling, and clinical examinations in their new follow-ups using common protocols. The cohorts have worked together intensively and have pooled data as part of other European Community (EC) projects (Larsen et al. 2013; Vrijheid et al. 2012; see also Supplemental Material, Previous EU projects contributing data and expertise to HELIX, pp. 2-3). The selection of cohorts followed a strategy to obtain data in different regions of Europe.

Study populations. In general, exposure estimates can be obtained in cohort studies for very large numbers of subjects by exposure models and questionnaires, whereas exposure and omics biomarkers can, for cost reasons, be obtained only in smaller numbers of subjects. Assessment of individual exposure variability and validation of exposure models require very intensive data collection that is feasible only in an even smaller number of subjects. For these reasons, HELIX uses a multilevel study design, drawing on nested study populations for four different levels of data collection (Figure 3), as follows:
1) The entire six cohorts comprising 32,000 mother-child pairs will form the basis of existing data. From this study population we will use existing exposure data such as tobacco use, ESCAPE (European Study of Cohorts for Air Pollution Effects) air pollution land-use regression (LUR) models (Eeftens et al. 2012), water disinfection by-products (DBPs) exposure models from the HiWate project (Health Impacts of long-term exposure to disinfection byproducts in drinking water) (Nieuwenhuijsen et al. 2009), confounder data, and outcome data. Outdoor exposure estimates (research area 2, below) will be applied to these entire cohorts. Risk estimates for the effects of combined outdoor exposures (the "outdoor exposome") on child health will be obtained in this study population. Harmonization of the existing data will build on protocols and expertise developed in earlier collaborative EC projects (Bousquet et al. 2011; Eeftens et al. 2012; Larsen et al. 2013; Vrijheid et al. 2012; see also Supplemental Material, Previous EU projects contributing data and expertise to HELIX, pp. 2-3). Outcomes that can be harmonized across cohorts include birth outcomes; postnatal growth and body mass index (BMI); self reported wheezing, doctor-diagnosed asthma, and measures of lung function; and neurodevelopment harmonized as five neurodevelopmental constructs (general cognition, language development, motor abilities, socioemotional behavior, and attention deficit/ hyperactivity disorder symptomatology) across different age groupings.
2) A HELIX subcohort of 1,200 mother-child pairs (Figure 3) will be fully characterized for the external and internal exposome, including exposure biomarkers during pregnancy and childhood and omics biomarkers during childhood. The impact of the total early-life exposome on child health will be characterized in these 1,200 mother-child pairs. The 1,200 mother-child pairs will be nested within the entire cohorts by selection of 200 pairs from each cohort. Eligibility criteria include $a$ ) age $6-9$ years, $7-8$ years, if possible; the age range should be as narrow as possible for comparability of omics analyses and exposure-related behavior; b) stored pregnancy blood and urine samples available, and available sample volume sufficient for the analysis of exposure biomarkers detailed in research area $1 ; c$ ) complete address history available from first to last follow-up point; $d$ ) no serious health problems that, in the opinion of a local clinician, may affect the performance of the clinical testing (e.g., spirometry) or affect the volunteer's safety (e.g., renal failure, pneumonia). In addition, the selection will consider whether data on important covariates (genetic data, diet, socioeconomic factors) are available. Cohorts with more than the required number of mother-child pairs that meet these criteria will invite subjects at random from the eligible pool. The new follow-up examination will include the collection of new biological samples suitable for all planned biomarker and omics analyses (research areas 1 and 4, below). The collection of two urine samples (one before bedtime and one first morning void) will better

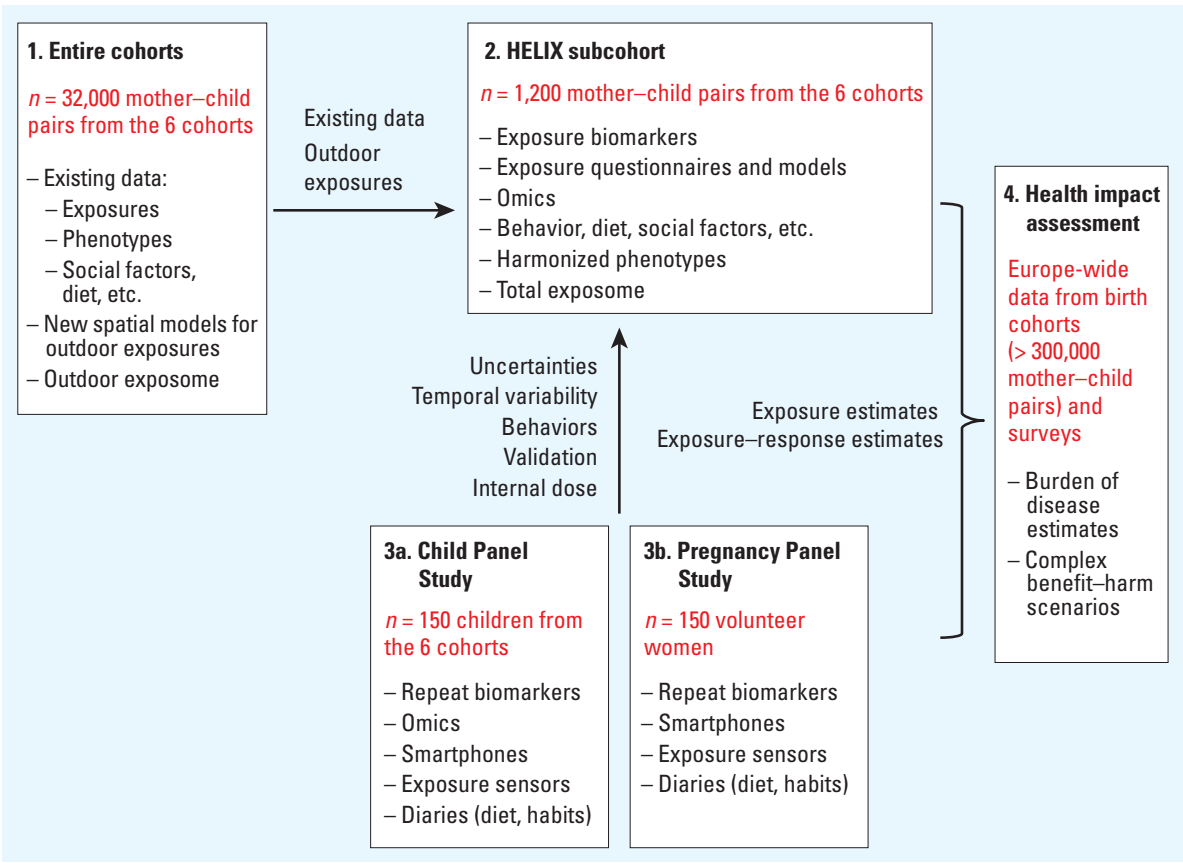

Figure 3. Study design, study populations, and data sources. 
capture short-lived biomarker metabolites and provide more stable metabolome coverage than would be achieved with one spot urine sample. Collected blood samples will be processed into appropriate matrices (including whole blood, serum, and plasma) and storage media (for RNA and DNA extraction), and will be rapidly deep frozen under optimized and standardized processing procedures. Variables that can affect omics profiles, such as use of drugs, time of last meal, or physical exercise, will be collected. Trained nurses will carry out health examinations of the children. Examinations include measurements of weight, height, waist circumference, skin folds, blood pressure, and spirometry, and will follow standard operating procedures. Standardized computer-assisted interviews with the mothers will collect information on exposure sources (smoking, cooking, heating, water consumption), physical activity, time activity, diet, social factors, stress, and asthma and allergy. Neurodevelopmental outcomes will be assessed through a battery of internationally standardized, nonlinguistic, and culturally blind computer tests [ $n$-back (Vuontela et al. 2003), Attention Network Test (Rueda et al. 2004), Trail Making Test (Lezak 2004), Raven (Raven et al. 1998)]. Parents will complete the Conners Comprehensive Behavior Rating Scales (Conners 1997) and Child Behavior Checklist (CBCL; Achenbach and Rescorla 2000) questionnaires to assess child behavioral problems. Besides the standardization of procedures and questionnaires, the project will implement data collection QA/QC (quality assurance/quality control) through the central training of nurses and field workers-including training workshops with harmonization and reliability exercises (e.g., for the skinfold measurements) and through visits of coordinators to the local cohorts during the fieldwork to monitor adherence to the standard operating procedures.

3) Panel studies (Figure 3) will collect data on short-term temporal variability in exposure biomarkers and omics biomarkers, on individual behaviors (physical activity, mobility, time activity), and on personal and indoor exposures. A "Child Panel Study" (Figure 3) will include children from the HELIX subcohort ( $n=150 ; 25$ from each cohort) and will thus be based on the same inclusion criteria. An added requirement for the panel study is that children must be able to wear equipment without destroying it. Invitations will be sent to all families included in the subcohort; but because of the intensive monitoring involved, it is expected that only the most cooperative families will agree to participate, so randomness cannot be guaranteed. Detailed information allowing discussion if the panel study differs from the larger groups will be available. A "Pregnancy Panel Study" (Figure 3) will include 150 pregnant women, 50 from three of the regions under study, and these will be volunteer women from outside the cohorts; mothers from the cohorts cannot be used for this purpose because their pregnancies occurred several years previously. Criteria for inclusion are singleton pregnancy, age $\geq 18$ years at the time of start of pregnancy, first visit to be conducted before week 20 of the pregnancy, and residence in the study area covered by the cohort. Study areas will be defined, taking into account the availability of fine-scale air pollution models; as far as possible the areas should correspond to the study areas of the original cohorts, or at least cover similar areas.

Subjects in the two panel studies will be followed for 1 week in two seasons. From these subjects we will collect daily urine samples-first morning and last nighttime voids, and from the pregnant women an additional midday void if possible. At the end of each monitoring week, blood samples will be collected following the same procedures as for the subcohort. Subjects or their mothers will complete diaries to collect information on meal times, cosmetics and medication use, and urination frequency for input into the physiologically based pharmacokinetic (PBPK) models (described under research area 1, below). The subjects will carry smartphones and personal monitors, and indoor air and noise monitors will be installed in the homes (research area 2). Additional QA/QC procedures in the panel studies will ensure that the two monitoring periods follow the same procedures in all cohorts and that blood is collected at approximately the same time of the day and under the same conditions in both periods and in all cohorts. This is important to reduce variability in the omics analyses.

4) Health impacts for the larger European population will then be estimated using the exposure levels and dose-response relations from HELIX (Figure 3), together with dose-response and threshold estimates from the literature and prevalence data from European registries and birth cohorts (Vrijheid et al. 2012).

\section{Measuring the External Exposome}

Accurate assessment of environmental exposures (reduction of exposure misclassification) remains an important outstanding challenge for health risk and impact assessment. In developing the exposome concept, this challenge is multiplied because it requires obtaining exposure data for many different exposures. Within the external exposome, a distinction can be made between largely individually assessed exposures such as ETS, water contaminants, persistent organic pollutants (POPs), pesticides, and metals, which are traditionally assessed through questionnaires and/or biomonitoring on an individual basis, and exposures in the outdoor environment such as outdoor air pollutants and noise, where, so far, the residence is taken for estimation of exposure, ignoring mobility.

Research area 1: individual exposures. Individually assessed exposures can vary on an hourly or daily to yearly basis. Temporal variability is particularly high for exposures with a short biological half-life and little constancy in the underlying exposure behavior [e.g., bisphenol A (BPA), phthalates, organophosporous pesticides (Bradman et al. 2013; Braun et al. 2011; Philippat et al. 2013; Preau et al. 2010)]. For such exposures, intra- compared with interindividual variability is known to be high, and only many repeat measurements over time may give improved exposure estimates. For more persistent exposures, biomarkers give more long-term exposure estimates that are influenced by changes in diet or behavior, for example, by breastfeeding patterns. Research area 1 will measure exposure biomarkers in the subcohort $(n=1,200)$ in appropriate biological samples newly collected from the children and previously collected from mothers during pregnancy. Biomarkers include POPS-PCBs (polychlorinated biphenyls), dichlorodiphenyldichloroethylene (DDE), hexachlorobenzene (HCB), polybrominated diphenyl ethers (PBDEs), perfluoroalkyl substances (PFASs) - in blood samples, nonpersistent chemicals - phthalates, phenols, organophosphate pesticides - in urine samples, metals in blood, and cotinine as a biomarker of ETS exposure (Table 1). Pre- and postnatal questionnaires will collect information on water consumption habits, which will be combined with information on concentrations of DBPs in drinking water from water companies to obtain estimates of exposure to DBPs. Questionnaires will also collect information on sources of indoor air pollution including ETS, cooking and heating appliances, and ventilation (Table 1). In the panel studies, indoor air pollution will be measured to characterize errors when using exposure information from questionnaires and models. This will be done using passive samplers for nitrogen dioxide $\left(\mathrm{NO}_{2}\right)$ and BTEX (benzene, toluene, ethylene, and xylene), and active $\mathrm{PM}_{2.5}$ (particulate matter with diameter $\leq 2.5 \mu \mathrm{m}$ ) cyclone pumps, installed in the home. The panel studies will measure daily repeat biomarkers of the nonpersistent 
chemicals (phthalates, phenols, organophosphate pesticides) in urine (Table 1); these data will be used to characterize inter- and intraindividual variability in these urine biomarkers, and where possible, correct for the uncertainties in the larger cohort.

One further source of uncertainty in exposure estimates based on biomarker concentrations is their relationship to the internal biologically effective dose (Sobus et al. 2011). The measured biomarker concentration cannot always be considered as a steady-state concentration (particularly for nonpersistent chemicals), nor as a surrogate for the internal dose of the target tissue and has often not been sampled during the entire critical time window (Bartell et al. 2004; Clewell et al. 2008). Here, modeling the toxicokinetics of the chemical using PBPK may help the interpretation of the measured biomarker data. PBPK models describe the fate of chemicals in the body using individual-specific information about the physiology (age, sex, weight) and the biochemistry (enzyme content) of the individual as well as information on the individual's behavior (breastfeeding, physical activity, diet) (Beaudouin et al. 2010). In the context of population (epidemiological) studies, PBPK models can be used to simulate exposure during critical time periods in between biomarker measurement points (e.g., Gascon et al. 2013b; Lyons et al. 2008; Ulaszewska et al. 2012).
To be relevant, this approach requires detailed input data on individual characteristics and behaviors to minimize assumptions and uncertainties. HELIX will evaluate the use of PBPK modeling to interpret biomarkers of exposure to PFASs [perfluorooctane sulfonate (PFOS), perfluorooctanoic acid (PFOA), and di(2-ethylhexyl) phthalate (DEHP)]. For the PFASs, we propose to relate the biomarker measurement in the child to that in the mother during pregnancy using an exposure scenario that integrates maternal-fetal transfers during pregnancy, transfers via breast milk, and diet during childhood. For DEHP, repeat biomarkers in the panel studies and information on exposure-related behaviors and urination times will be used to evaluate the predictable value of different numbers of biomarker measurements.

Research area 2: outdoor exposures. For exposures that are traditionally assessed on the basis of residential location, such as outdoor air pollutants, noise and the built environment, major improvements in exposure assessment and reduction in measurement error can be achieved by collecting information on time-space activity, and, in the case of air pollution, on how much air a person inhales. Knowledge on physical activity, which constitutes a proxy of the inhalation rate (Kawahara et al. 2011), for example, may be integrated with personal air pollution measurements to estimate inhalation dose.
New geographic information system (GIS)based exposure assessments (Beelen et al. 2013; Eeftens et al. 2012), remote sensing (Dadvand et al. 2012), and smartphone technologies (de Nazelle et al. 2013) have made it easier to assess outdoor exposures, and to integrate personal mobility and physical activity data.

Research area 2 will construct a GIS environment for the six cohorts, and will assign exposure estimates for air pollutants, noise, ultraviolet (UV) radiation, temperature, built environment/green spaces. The estimates will build on existing LUR air pollution maps (Beelen et al. 2013; Eeftens et al. 2012), noise maps, UV index and METEOSAT data, green space estimates, as well as walkability, building density, and bike lane map information for the built environment (Table 2). Data from existing regulatory monitors and remote sensing data (e.g., from the Tropospheric Emission Monitoring Internet Service; http:// www.temis.nl/) will be used to inform ambient spatial exposure models. The aim is to obtain average exposure estimates for the pregnancy period, and during childhood for different time periods, including 1 day, 1 week, 1 month, and 1 year before the outcome and omics assessment. Smartphones will be worn by the participants in the panel studies to provide geolocation data every second and the metabolic equivalent of tasks (METs)

Table 1. Individual exposures.

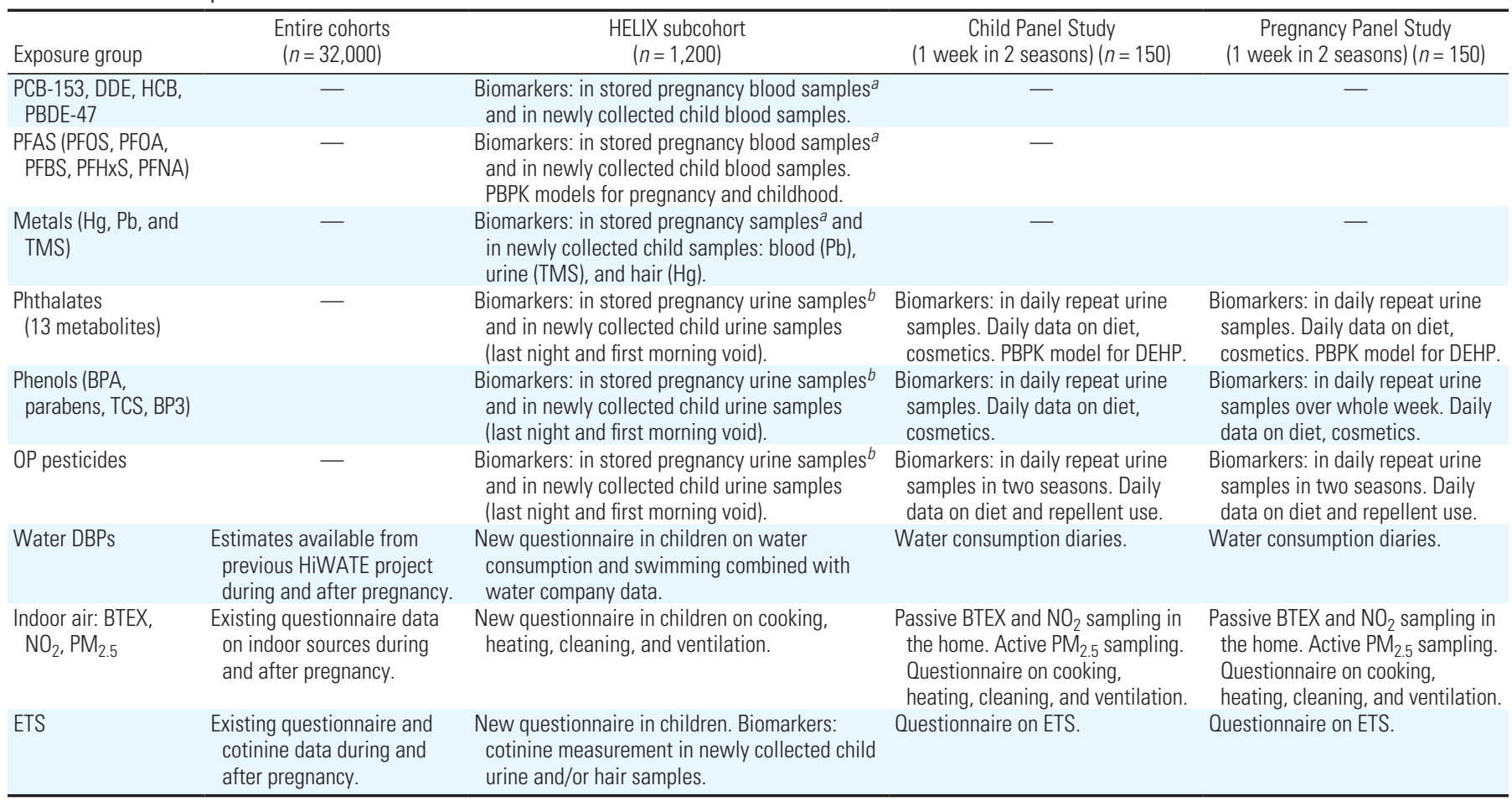

Abbreviations: BP3, benzophenone-3; BPA, bisphenol A; BTEX, benzene, toluene, ethylbenzene, xylene; DBPs, disinfection by-products; DDE, dichlorodiphenyldichloroethylene; DEHP, $\mathrm{di}\left(2\right.$-ethylhexyl) phthalate; ETS, environmental tobacco smoke; $\mathrm{HCB}$, hexachlorobenzene; $\mathrm{Hg}$, mercury; $\mathrm{NO}_{2}$, nitrogen dioxide; OP, organophospate pesticides; $\mathrm{Pb}$, lead; $\mathrm{PBDE}-47$, polybrominated diphenyl ether-47; PCB-153, polychlorinated biphenyl-153; PFAS, perfluoroalkyl substances; PFBS, perfluorobutanesulfonic acid; PFHxS, perfluorohexane sulfonic acid; PFNA, perfluorononanoic acid; PFOA, perfluorooctanoic acid; PFOS, perfluorooctane sulfonic acid; TCS, triclosan; TMS, total metal spectrum.

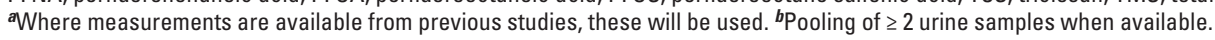


every $10 \mathrm{sec}$, derived from the built-in accelerometer and GPS (global positioning system) and integrated on the specially developed ExpoApp (Ateknea Solutions Catalonia S.A., Barcelona, Spain). We will then translate these data into activity type (resting, cycling, car travel) and derive inhalation rates. The panel study subjects will also wear electronic wrist band UV dosimeters (Seckmeyer et al. 2011), $\mathrm{PM}_{2.5}$ active samplers (DCG4004 sampling pump with GK.05SH Cyclone inlet; BGI Instruments, Waltham, MA, USA), and MicroAthelometers (AE-51; Envirodata, Madrid, Spain) for continuous black carbon monitoring (Table 2). Personal exposure estimates will be used to characterize uncertainties in the spatial exposure models.

\section{Integrating the External and Internal Exposome}

Research area 3: integrating exposures. Once individual and outdoor exposures have been estimated, research area 3 will use analysis-ofvariance techniques, incorporating data from both the HELIX subcohort and the panel studies, to understand the variance components for each key exposure (e.g., arising from diet, physical activity, or time of sampling) and describe the uncertainties in each of the exposure estimates. Statistical techniques such as factor analysis and latent class analysis will be used to create a reduced set of continuous exposure indices based on commonly occurring exposures, while individuals who share similar exposure profiles or "exposomes" will be defined. We will then determine the influence of variables such as diet, socioeconomic status, study region, and seasonality on these exposure indices or profiles. Specific attention will be given to the detection of cohortspecific exposure patterns.

Research area 4: integrating molecular exposure signatures. High-throughput molecular biology "omics" techniques (such as metabolomics, proteomics, transcriptomics, epigenomics) have important potential for broad and untargeted characterization of the internal exposome (Ellis et al. 2012; Hebels et al. 2013). Here, the interest is in the identification of exposure biomarkers and mechanistic pathways. Research area 4 will determine molecular signatures associated with environmental exposures through the measurement of endogenous and xenobiotic metabolite profiles in blood and urine, proteins in plasma, and coding and small noncoding RNAs (including miRNAs; microRNAs) and DNA methylation in whole blood. Omics tools will be employed mainly in the subcohort of 1,200 children with newly collected biosamples at 6-9 years of age; the use of new samples ensures comparability between techniques and cohorts (Figure 4, Table 3; see also Supplemental Material, Detailed description of omics techniques to be used in HELIX, pp. 4-6). The use of a similar time point for all omics techniques also allows integration of the different techniques during data analysis. Genotyping is available already in most of the cohorts and will be completed where needed. Two main limitations in epidemiological studies aiming to use omics biomarkers are tissue and intraindividual variability. Omics profiles are tissue specific, and the tissue of interest can usually not be obtained (e.g., adipose tissue, brain tissue). The focus of HELIX is thus on markers in systemic biological samples (blood, urine) to evaluate the use of omics biomarkers as markers of exposure changes in (larger) epidemiological studies. Omics profiles change over time in the same person; a cross-omics paper with three repeat analyses in 16 subjects over 1 month showed that intraindividual variability for metabolomics and transcriptomics was found to be lower than interindividual variability for almost all the biomarkers (Gruden et al. 2012). However, some sets of markers were highly variable within the same subject and thus cannot be used directly in epidemiological studies. Further, longer time periods of 1 month are likely to give higher intraindividual variability. HELIX will make some progress toward characterizing intra- and interindividual variability in the metabolomics and transcriptomics markers by analyzing repeat biological samples collected in the panel studies in different seasons.

The omics work will be implemented in three general stages:

Stage 1: Study design optimization. Biological samples collected in the panel studies (daily urine samples, two blood samples) will be used to assess detectability of omics markers and the likely sources of variability within and between individuals, using small numbers of subjects. These results will inform the design and interpretation of stages 2 and 3 .

Stage 2: Omics-exposure associations in the biological samples newly collected in the subcohort $(n=1,200)$. Primary analyses will

Table 2. Outdoor exposures.

\begin{tabular}{|c|c|c|c|c|}
\hline Exposure group & $\begin{array}{c}\text { Entire cohort ( } n=32,000) \text {, for } \\
\text { pre- and postnatal exposure periods }\end{array}$ & $\begin{array}{l}\text { Subcohort } \\
(n=1,200)\end{array}$ & $\begin{array}{c}\text { Child Panel Study } \\
\text { (1 week in } 2 \text { seasons) }(n=150)\end{array}$ & $\begin{array}{c}\text { Pregnancy Panel Study } \\
\text { (1 week in } 2 \text { seasons) }(n=150)\end{array}$ \\
\hline $\begin{array}{l}\text { Ambient air } \\
\text { pollutants }\end{array}$ & $\begin{array}{l}\text { LUR model for } \mathrm{NO}_{2}, \mathrm{PM}_{2.5}, \mathrm{PM}_{10} \\
\mathrm{PM}_{\text {coarse, }}, \mathrm{PM}_{2.5} \text { absorbance, } \mathrm{PM} \\
\text { elemental analyses. Routine } \\
\text { monitoring and } \mathrm{OMI} \text { satellite data } \\
\text { for temporal variability. }\end{array}$ & $\begin{array}{l}\text { LUR model for } \mathrm{NO}_{2}, \mathrm{PM}_{2.5}, \mathrm{PM}_{10} \\
\mathrm{PM}_{\text {coarse}}, \mathrm{PM}_{2.5} \text { absorbance, } \mathrm{PM} \\
\text { elemental analyses. Routine } \\
\text { monitoring and OMl satellite data } \\
\text { for temporal variability. }\end{array}$ & $\begin{array}{l}\text { Inhalation rates and mobility (GPS) } \\
\text { data from smartphones. Personal } \\
\text { monitoring ( } 24 \mathrm{hr} \text { ) of } \mathrm{PM}_{2.5} \text { (and } \\
\text { black carbon. }\end{array}$ & $\begin{array}{l}\text { Inhalation rates and mobility } \\
\text { (GPS) data from smartphones. } \\
\text { Personal monitoring ( } 24 \mathrm{hr} \text { ) of } \\
\mathrm{PM}_{2.5} \text { and black carbon. }\end{array}$ \\
\hline Noise & $\begin{array}{l}\text { Existing municipal noise maps to } \\
\text { obtain spatial estimates. Address- } \\
\text { based modeling of noise at the most } \\
\text { and least exposed facade. }\end{array}$ & $\begin{array}{l}\text { New questionnaires in children on } \\
\text { bedroom position, noise perception, } \\
\text { etc. Noise estimates based on maps } \\
\text { and questions. }\end{array}$ & $\begin{array}{l}\text { Time-activity and mobility (GPS) data } \\
\text { from smartphones. }\end{array}$ & $\begin{array}{l}\text { Time-activity and mobility } \\
\text { (GPS) data from smartphones. }\end{array}$ \\
\hline UV & $\begin{array}{l}\text { Remote sensing (satellite) UV } \\
\text { radiation maps. }\end{array}$ & $\begin{array}{l}\text { New questionnaires in children on } \\
\text { traveling, use of sunscreens, clothes, } \\
\text { skin color. UV radiation estimates } \\
\text { based on maps and questions. }\end{array}$ & $\begin{array}{l}\text { Time-activity and mobility (GPS) } \\
\text { data from smartphones and } \\
\text { questionnaires. Personal monitoring } \\
\text { using electronic UV dosimeters. }\end{array}$ & $\begin{array}{l}\text { Time-activity and mobility } \\
\text { (GPS) data from smartphones } \\
\text { and questionnaires. Personal } \\
\text { monitoring using electronic UV } \\
\text { dosimeters. }\end{array}$ \\
\hline Temperature & $\begin{array}{l}\text { Remote sensing (satellite) } \\
\text { temperature maps (from thermal } \\
\text { infrared band) and data from local } \\
\text { meteorological stations. }\end{array}$ & $\begin{array}{l}\text { New questionnaires in children } \\
\text { on heating and air conditioning. } \\
\text { Temperature estimates based on } \\
\text { maps and questions. }\end{array}$ & $\begin{array}{l}\text { Time-activity and mobility (GPS) } \\
\text { data from smartphones and } \\
\text { questionnaires. Personal monitoring } \\
\text { of temperature using electronic } \\
\text { dosimeters. }\end{array}$ & $\begin{array}{l}\text { Time-activity and mobility } \\
\text { (GPS) data from smartphones } \\
\text { and questionnaires. Personal } \\
\text { monitoring of temperature } \\
\text { using electronic dosimeters. }\end{array}$ \\
\hline $\begin{array}{l}\text { Built environment/ } \\
\text { green spaces }\end{array}$ & $\begin{array}{l}\text { Normalized Difference Vegetation } \\
\text { Index from satellite. Building density, } \\
\text { walkability score, accessibility, bike } \\
\text { lanes, etc., derived from GIS data. }\end{array}$ & $\begin{array}{l}\text { New questionnaires in children on } \\
\text { use of green spaces, public spaces, } \\
\text { active transportation. }\end{array}$ & $\begin{array}{l}\text { Time-activity and mobility (GPS) } \\
\text { data from smartphones and } \\
\text { questionnaires. }\end{array}$ & $\begin{array}{l}\text { Time-activity and mobility } \\
\text { (GPS) data from smartphones } \\
\text { and questionnaires. }\end{array}$ \\
\hline
\end{tabular}

Abbreviations: GIS, geographic information system; GPS, global positioning system; LUR, land use regression; $\mathrm{NO}_{2}$, nitrogen dioxide; $\mathrm{NO}_{\mathrm{x}}$, nitrous oxides; OMI, ozone monitoring

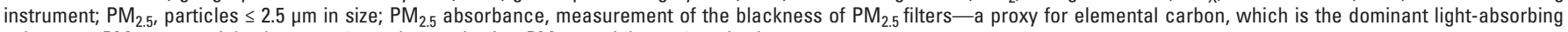
substance; $\mathrm{PM}_{\text {coarse, }}$ particles between 2.5 and $10 \mu \mathrm{m}$ in size; $\mathrm{PM}_{10}$, particles $\leq 10 \mu \mathrm{m}$ in size. 
evaluate three a priori defined exposures (ETS, total POP concentration, and air pollution) and on the specific multiple exposure clusters generated in research area 3 . The three exposures have been selected because we have comparatively good long-term exposure estimates, and already there are some data from human omics studies (Bollati and Baccarelli 2010; Hou et al. 2011, 2012; Rusiecki et al. 2008). Power calculations for these analyses are described in the Supplemental Material, Detailed description of omics techniques to be used in HELIX, pp. 4-6, and Table S1. Secondary analyses will examine other exposures. Panel study data will evaluate short-term exposure-omics associations for a range of exposures for which detailed data are collected in the panels: air pollution, noise, UV, and nonpersistent chemicals.

Stage 3. Omics-health associations. Biologically meaningful omics "hits" will be then linked to our main child health end points, similar to the "meet-in-the-middle" approach to biomarker discovery (ChadeauHyam et al. 2011). The child health outcomes will be largely continuous outcome scores (BMI $z$-score, cognitive score, lung function). If relevant, reverse causality potential may be evaluated in blood and urine samples available in some of the cohorts at earlier time points (Figure 4).

To analyze, integrate, and interpret the large numbers of data generated by individual omics techniques, HELIX will apply a pathway analysis approach. The biomarkers obtained from the association analysis, in combination with available libraries of biological pathways [Gene Ontology (http://www. geneontology.org/); Kyoto Encyclopedia of Genes and Genomes (http://www.genome. jp/kegg/); Reactome (http://www.reactome. org/); Comparative Toxicogenomics Database (http://ctdbase.org/)] will be used to identify biological pathways affected by the exposures. Identification and representation of biologicaltoxicological pathways will be done using software such as Ingenuity Pathway Analysis (http://www.ingenuity.com/), Cytoscape (Saito et al. 2012), and Impala (Kamburov et al. 2011). Pathway approaches combining data from different omics techniques (e.g., metabolomics and transcriptomics) are also starting to be developed to search for common pathways determining sensitivity to pharmaceutical and toxic agents (Cavill et al. 2011; Jennen et al. 2011; Kamburov et al. 2011); HELIX aims to use similar approaches.

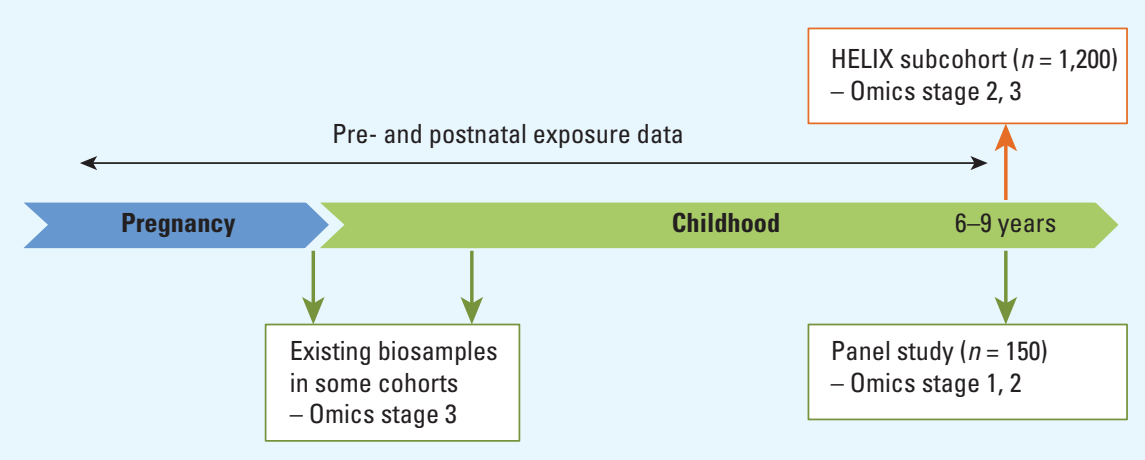

Figure 4. Timeline of the omics analysis.

\section{Associating the Exposome with Child Health}

Finally, one of the greatest challenges of the exposome concept lies in the assessment of its association with health outcomes: How can we integrate multidimensional exposome data to draw meaningful conclusions about (child) health impacts? In general, environmental health studies have considered single exposures or single families of exposure (e.g., atmospheric pollutants, drinking-water pollutants). Notable exceptions of studies that have provided risk estimates for multiple exposures include a cross-sectional EWAS of diabetes (Patel et al. 2010, 2013) and a study by Budtz-Jørgensen et al. (2010) that considered both PCBs and mercury. Statistical analyses that consider many exposure variables simultaneously in a naïve (agnostic) way, such as the EWAS, strongly increase the risk of observing random associations (false positives) because of multiple testing, and of underestimating the global effect of the environment. In developing statistical tools for the analysis of many exposure factors, we should draw important lessons from the achievements but also the limitations (Shi and Weinberg 2011) of the parallel genome-wide association studies (GWAS) field, particularly regarding the probably weak efficiency of purely agnostic approaches, the very large sample sizes required, and the need to use complementary approaches (e.g., pathway analysis) making use of a priori information.

Further, the exposome includes evaluation of multiple exposures, omics markers, and outcomes, each with very different temporal scenarios. A challenge in the development of the statistical analysis protocols is to takes these complexities into account. For example, spatial models for the outdoor exposures are constructed for a specific year and can then be extrapolated to relevant time periods (days, weeks, months, or years) backward or forward

Table 3. Omics analyses. ${ }^{a}$

\begin{tabular}{|c|c|c|c|}
\hline Omics technique & $\begin{array}{l}\text { Entire cohort } \\
(n=32,000)\end{array}$ & Subcohort ( $n=1,200$ mother-child pairs) & Child Panel Study (1 week in 2 seasons) $(n=150)^{b}$ \\
\hline Metabolomics & - & $\begin{array}{l}\text { Untargeted }{ }^{1} \mathrm{H} \text { NMR spectroscopy and semitargeted UPLC-MS } \\
\text { analysis in urine; targeted analysis in serum (using Biocrates } \\
\text { Absolute ID0 p180 Kit) in newly collected child samples. }\end{array}$ & $\begin{array}{l}\text { Further analysis of daily urine samples and single serum sample at the } \\
\text { end of each week (in winter and summer seasons) to evaluate sources } \\
\text { of variation and short-term exposure-omics associations. }\end{array}$ \\
\hline Proteomics & - & $\begin{array}{l}\text { Targeted analysis in newly collected child plasma samples } \\
\text { depending on results of analysis in the Child Panel Study. }\end{array}$ & $\begin{array}{l}\text { Initial iTRAO and MRM (or similar) analyses in plasma samples collected } \\
\text { at end of each week (in winter and summer seasons) to evaluate } \\
\text { sources of variation and short-term exposure-omics associations. }\end{array}$ \\
\hline Transcriptomics & - & $\begin{array}{l}\text { Next-generation sequencing (llumina Hiseq2000) or microarray } \\
\text { analysis of both mRNAs and miRNAs in newly collected child } \\
\text { whole blood samples. In addition, plasma will be collected to } \\
\text { analyze miRNAs in the future. }\end{array}$ & $\begin{array}{l}\text { Analysis of blood samples at the end of each week (in winter and summer } \\
\text { seasons) to evaluate sources of variation and short-term exposure- } \\
\text { omics associations. In addition, plasma will be collected to analyze } \\
\text { miRNAs in the future. }\end{array}$ \\
\hline DNA methylation & - & $\begin{array}{l}\text { Infinium Human Methylation } 450 \text { BeadChip for genome-wide } \\
\text { methylation analysis of DNA extracted from newly collected } \\
\text { child whole blood samples. }\end{array}$ & $\begin{array}{l}\text { Analysis of blood samples at the end of each week (in winter and summer } \\
\text { seasons) to evaluate sources of variation and short-term exposure-- } \\
\text { omics associations. }\end{array}$ \\
\hline
\end{tabular}

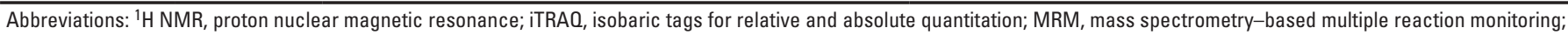
miRNA, microRNA; mRNA, messengerRNA; UPLC-MS, ultra performance liquid chromatography-mass spectrometry.

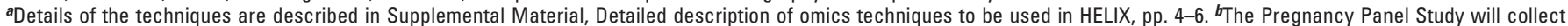

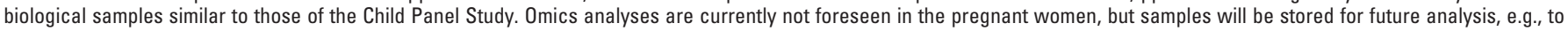
evaluate whether specific omics findings from the children are replicated in the pregnant women. 
in time using available monitoring stations data. For persistent pollutants we may assume that biomarkers give estimates over a relatively long time period, whereas for nonpersistent pollutants biomarkers will reflect only very recent exposures; in some cases we may assume a fairly constant exposure pattern depending on the habits underlying the exposure (e.g., cosmetics use, dietary patterns), whereas in other cases exposure variations may be largely seasonal (e.g., sunscreens, pesticides). Neurodevelopment, growth and obesity, and asthma and allergies are each driven by extremely complex multistage developmental processes that take place prenatally and during the first years of postnatal life. Commonly used statistical techniques for high-dimensional data, such as machine learning, dimension reduction, and variable selection techniques, need to be adapted to the longitudinal context by accommodating issues such as time-varying exposure effects, delayed effects, and effects of exposure trajectories over time on outcome trajectories (Buck Louis and Sundaram 2012).

Research area 5: linking the exposome to child health. Research area 5 aims to develop a multistep approach that is based on several tools and methods and will produce risk estimates for different types of exposure variables:

1) Many single-exposure variables: This is an agnostic EWAS approach with no a priori information, in which all pairs of exposure-outcome associations will be quantified (using classical regression models), appropriately controlling for false discovery rate (FDR), as is done in GWAS and in the only published EWAS (Patel et al. 2010, 2013); spline and other smoothing models (Slama and Werwatz 2005) will then look for possible thresholds in dose-response relationships.

2) Combined exposure variables: This is an SEM approach (Budtz-Jørgensen et al. 2010) in which synthetic exposure variables will be built based on previous knowledge summarized by directed acyclic graphs. Several sets of synthetic exposure variables will be considered, including those based on common exposure pathways (e.g., indoor and outdoor air pollutants), on exposure patterns generated by the project, and on knowledge of biological pathways.

3) Groups of subjects sharing a similar exposome: This approach involves Bayesian profile regression, which aims to identify groups of individuals sharing a similar exposome that at the same time show marked differences according to the health outcome variable of study (Molitor et al. 2010; Papathomas et al. 2011). This is achieved by fitting model-based clustering to the exposure data, while allowing the outcome of interest to influence cluster membership.
This technique was used, for example, to identify as a high-risk set for lung cancer a cluster of subjects characterized by their living close to a main road, high exposure to $\mathrm{PM}_{10}$ (particulate matter with diameter $\leq 10 \mu \mathrm{m}$ ) and $\mathrm{NO}_{2}$, and carrying out manual work (Papathomas et al. 2011). This technique considers the exposome as a whole instead of breaking up risks for individual exposures, and is therefore able to capture effects and complex interactions and combinations of exposures that cannot be detected with the EWAS approach.

SEMs and Bayesian profile regression models will also be used to account for the effects of exposure measurement error and uncertainty, in addition to more classical measurement error models such as regression calibration. The general idea is that these techniques treat exposures not as a fixed value, but as a distribution that can be informed from the repeated measurements (e.g., of nonpersistent pollutants) and personal measurements (e.g., of air pollutants) in the panel studies. As a preliminary step, a simulation study aimed at comparing the efficiency of various study designs and statistical approaches to characterize the impact of the exposome on health will be conducted. With a sample size of 1,200 (subcohort), the agnostic EWAS analysis with control for FDR will have a power of $80 \%$ to detect a 3-point difference in a continuous outcome variable with a standard deviation of 15 (as in common neurodevelopment indexes), considering that $15 \%$ of the tested exposures will show an association (Liu and Hwang 2007). Higher power will be achieved for exposures available for more subjects (e.g., air pollution) and more hypothesis-driven analyses.

Heterogeneity between cohorts in terms of study design can play a role in the results of these analyses, but it will not be possible to separate these effects from true differences between populations. We will address the issue of cohort differences in two ways: a) We will center all exposures using the cohort mean. Analyses conducted with mean-centered variables will remove differences between cohorts and only consider within-cohort differences in exposure. b) We will document heterogeneity between cohorts, applying random effects models where applicable, and conduct sensitivity analyses excluding one cohort at the time.

Research area 6: health impact of multiple exposures. Finally, research area 6 will estimate the burden of common childhood diseases that may be attributed to multiple environmental exposures in Europe. It will construct scenarios for the health impact assessment, working from traditional one-exposure-oneoutcome assessments (e.g., traffic-related air pollution and asthma; mercury and neurodevelopment) to more complex benefitharm scenarios. For example, given increasing obesity rates, children are encouraged to walk or cycle to school, which may lead to increased energy expenditure and possible reduction in weight and improvement in mental health. However, at the same time, longer duration of exposure to air pollutants, noise, and UV may lead to adverse health effects and higher risks of accidents (Rojas-Rueda et al. 2012). Do the overall benefits outweigh these risks, and what should policy makers do to improve these conditions of active transportation? This work will integrate exposure, uncertainty, and biomarker data obtained in HELIX, risk estimates obtained in HELIX, exposure-response data from the literature, exposure data from other existing birth and child cohorts (Vrijheid et al. 2012) and Europe-wide surveys, and prevalence data from existing health registries/surveys in Europe. Expert workshops will be organized to obtain information.

Data warehouse. Data from the previous cohort follow-ups, the new follow-up when the children are 6-9 years of age, the panel studies, and the omics and biomarker analyses will be stored in a common, central database (data warehouse) with common, centrally established QA/QC procedures. Mechanisms to transfer and hold data from across cohorts and other partners will include the identification of agreed data sets, specifications for the data warehouse, data validation, cleaning and harmonization procedures, and the establishment of robust data security mechanisms. Data analysis protocols will be established and performed centrally by a statistical analysis task force. Further, the data warehouse will be established in a format that will allow future uses beyond the project as an accessible resource for researchers external to the project. Procedures for external access will be developed and made public by the end of the project; these will include information regarding data collection, data content, and procedures for data requests.

\section{Conclusions}

There is a strong consensus that new integrative tools and approaches for human exposure and risk characterization are needed to significantly advance environmental risk and health impact assessment and health protection (Cohen Hubal et al. 2010; Lioy and Rappaport 2011; National Research Council 2012). Specifically, new approaches are needed to measure and integrate a wide range of (known and unknown) chemical and physical exposures from different sources and link these to health. The exposome concept may be a useful paradigm for this. HELIX is one of the first attempts to describe the early-life exposome of European populations and unravel its relation to omics markers and 
health in childhood. As proof of concept, HELIX will be able to evaluate the many challenges in the implementation of the exposome concept and will form an important first step toward the description of the life-course exposome and its health effects

\section{REFERENCES}

Achenbach TM, Rescorla LA. 2000. Manual for the ASEBA Preschool Forms and Profiles. Burlington, VT:University of Vermont Department of Psychiatry.

Barouki R, Gluckman PD, Grandjean P, Hanson M, Heindel JJ. 2012. Developmental origins of non-communicable disease: implications for research and public health. Environ Health 11:42; doi:10.1186/1476-069X-11-42.

Bartell SM, Griffith WC, Faustman EM. 2004. Temporal error in biomarker-based mean exposure estimates for individuals. J Expo Anal Environ Epidemiol 14:173-179.

Beaudouin R, Micallef S, Brochot C. 2010. A stochastic wholebody physiologically based pharmacokinetic model to assess the impact of inter-individual variability on tissue dosimetry over the human lifespan. Regul Toxicol Pharmacol 57(1):103-116.

Beelen R, Hoek G, Vienneau D, Eeftens M, Dimakopoulou K, Pedeli $\mathrm{X}$, et al. 2013. Development of $\mathrm{NO}_{2}$ and $\mathrm{NO}_{x}$ land use regression models for estimating air pollution exposure in 36 study areas in Europe-The ESCAPE project. Atmos Environ 72:10-23.

Bellinger DC. 2013. Prenatal exposures to environmental chemicals and children's neurodevelopment: an update. Saf Health Work 4(1):1-11.

Bollati V, Baccarelli A. 2010. Environmental epigenetics. Heredity 105(1):105-112.

Bousquet J, Anto J, Auffray C, Akdis M, Cambon-Thomsen A, Keil T, et al. 2011. MeDALL (Mechanisms of the Development of ALLergy): an integrated approach from phenotypes to systems medicine. Allergy 66(5):596-604.

Bradman A, Kogut K, Eisen EA, Jewell NP, Quiros-Alcala L, Castorina R, et al. 2013. Variability of organophosphorous pesticide metabolite levels in spot and 24-hr urine samples collected from young children during 1 week. Environ Health Perspect 121:118-124; doi:10.1289/ehp.1104808.

Braun JM, Kalkbrenner AE, Calafat AM, Bernert JT, Ye X, Silva MJ, et al. 2011. Variability and predictors of urinary bisphenol A concentrations during pregnancy. Environ Health Perspect 119:131-137; doi:10.1289/ehp.1002366.

Buck Louis GM, Sundaram R. 2012. Exposome: time for transformative research. Stat Med 31(22):2569-2575.

Budtz-Jørgensen E, Debes F, Weihe P, Grandjean P. 2010. Structural equation models for meta-analysis in environmental risk assessment. Environmetrics 21(5):510-527.

Cavill R, Kamburov A, Ellis JK, Athersuch TJ, Blagrove MS, Herwig R, et al. 2011. Consensus-phenotype integration of transcriptomic and metabolomic data implies a role for metabolism in the chemosensitivity of tumour cells. PLoS Comput Biol 7(3):e1001113; doi:10.1371/journal.pcbi.1001113.

Chadeau-Hyam M, Athersuch TJ, Keun HC, De lorio M, Ebbels TM, Jenab M, et al. 2011. Meeting-in-the-middle using metabolic profiling-a strategy for the identification of intermediate biomarkers in cohort studies. Biomarkers 16(1):83-88.

Chatzi L, Plana E, Daraki V, Karakosta P, Alegkakis D, Tsatsanis C, et al. 2009. Metabolic syndrome in early pregnancy and risk of preterm birth. Am J Epidemiol 170(7):829-836.

Clewell HJ, Tan YM, Campbell JL, Andersen ME. 2008. Quantitative interpretation of human biomonitoring data. Toxicol Appl Pharmacol 231(1):122-133.

Cohen Hubal EA, Richard A, Aylward L, Edwards S, Gallagher J, Goldsmith MR, et al. 2010. Advancing exposure characterization for chemical evaluation and risk assessment. J Toxicol Environ Health B Crit Rev 13(2-4):299-313.

Conners CK. 1997. Conners' Rating Scales-Revised Technical Manual. Toronto:Multi-Health Systems.

Dadvand P, Sunyer J, Basagaña X, Ballester F, Lertxundi A, Fernández-Somoano A, et al. 2012. Surrounding greenness and pregnancy outcomes in four Spanish birth cohorts. Environ Health Perspect 120:1481-1487; doi:10.1289/ ehp.1205244.

de Nazelle A, Seto E, Donaire-Gonzalez D, Mendez M Matamala J, Nieuwenhuijsen MJ, et al. 2013. Improving estimates of air pollution exposure through ubiquitous sensing technologies. Environ Pollut 176:92-99.

Drouillet $\mathrm{P}$, Kaminski M, De Lauzon-Guillain B, Forhan A Ducimetière $P$, Schweitzer $M$, et al. 2009. Association between maternal seafood consumption before pregnancy and fetal growth: evidence for an association in overweight women. The EDEN mother-child cohort. Paed Perinat Epidemiol 23(1):76-86

Eeftens M, Tsai M-Y, Ampe C, Anwander B, Beelen R, Bellander T, et al. 2012. Spatial variation of $\mathrm{PM}_{2.5}, \mathrm{PM}_{10}$ $\mathrm{PM}_{2.5}$ absorbance and $\mathrm{PM}_{\text {coarse }}$ concentrations between and within 20 European study areas and the relationship with $\mathrm{NO}_{2}$ - Results of the ESCAPE project. Atmos Environ 62(0):303-317.

Ellis J, Athersuch T, Thomas L, Teichert F, Perez-Trujillo M, Svendsen C, et al. 2012. Metabolic profiling detects early effects of environmental and lifestyle exposure to $\mathrm{cad}$ mium in a human population. BMC Medicine 10(1):61 doi:10.1186/1741-7015-10-61.

Gallagher J, Hudgens E, Williams A, Inmon J, Rhoney S, Andrews $\mathrm{G}$, et al. 2011. Mechanistic indicators of child hood asthma (MICA) study: piloting an integrative design for evaluating environmental health. BMC Public Health 11:344; doi:10.1186/1471-2458-11-344.

Gascon M, Morales E, Sunyer J, Vrijheid M. 2013a. Effects of persistent organic pollutants on the developing respiratory and immune systems: a systematic review. Environ Int 52:51-65.

Gascon M, Verner MA, Guxens M, Grimalt JO, Forns J, Ibarluzea J, et al. 2013b. Evaluating the neurotoxic effects of lactational exposure to persistent organic pollutants (POPs) in Spanish children. Neurotoxicology 34:9-15.

Gluckman PD, Hanson MA. 2004. Living with the past: evolution, development, and patterns of disease. Science 305(5691):1733-1736.

Grazuleviciene R, Danileviciute A, Nadisauskiene R, Vencloviene J. 2009. Maternal smoking, GSTM1 and GSTT1 polymorphism and susceptibility to adverse pregnancy outcomes. Int J Environ Res Pub Health 6(3):1282-1297.

Gruden K, Hren M, Herman A, Blejec A, Albrecht T, Selbig J, et al. 2012. A "crossomics" study analysing variability of different components in peripheral blood of healthy Caucasoid individuals. PLoS One 7(1):e28761; doi:10.1371/ journal.pone.0028761.

Guxens M, Ballester F, Espada M, Fernández MF, Grimalt JO Ibarluzea J, et al. 2012. Cohort profile: the INMA—INfancia y Medio Ambiente-(Environment and Childhood) Project. Int J Epidemiol 41(4):930-940.

Hebels DG, Georgiadis P, Keun HC, Athersuch TJ, Vineis $\mathrm{P}$, Vermeulen $R$, et al. 2013. Performance in omics analyses of blood samples in long-term storage: opportunities for the exploitation of existing biobanks in environmental health research. Environ Health Perspect 121:480-487; doi:10.1289/ ehp.1205657.

Hines RN, Sargent D, Autrup H, Birnbaum LS, Brent RL, Doerrer NG, et al. 2010. Approaches for assessing risks to sensitive populations: lessons learned from evaluating risks in the pediatric population. Toxicol Sci 113(1):4-26.

Hou L, Wang D, Baccarelli A. 2011. Environmental chemicals and microRNAs. Mutat Res 714(1-2):105-112.

Hou L, Zhang X, Wang D, Baccarelli A. 2012. Environmental chemical exposures and human epigenetics. Int J Epidemiol 41(1):79-105.

Jennen D, Ruiz-Aracama A, Magkoufopoulou C, Peijnenburg A Lommen A, van Delft J, et al. 2011. Integrating transcriptomics and metabonomics to unravel modes-of-action of 2,3,7,8-tetrachlorodibenzo- $p$-dioxin (TCDD) in HepG2 cells. BMC Syst Biol 5:139; doi:10.1186/1752-0509-5-139.

Kamburov A, Cavill R, Ebbels TM, Herwig R, Keun HC. 2011. Integrated pathway-level analysis of transcriptomics and metabolomics data with IMPaLA. Bioinformatics 27(20):2917-2918.

Kawahara J, Tanaka S, Tanaka C, Aoki Y, Yonemoto J. 2011 Estimation of daily inhalation rate in preschool children using a tri-axial accelerometer: a pilot study. Sci Total Environ; 409(16):3073-3077

La Merrill M, Birnbaum LS. 2011. Childhood obesity and environmental chemicals. Mt Sinai J Med 78(1):22-48.

Larsen PS, Kamper-Jørgensen M, Adamson A, Barros $H$ Bonde JP, Brescianini S, et al. 2013. Pregnancy and birth cohort resources in Europe: a large opportunity for aetiological child health research. Paed Perinat Epidemio 27:393-414.

Lezak MD. Neuropsychological Assessment. 2004. New York:Oxford University Press.
Lioy PJ, Rappaport SM. 2011. Exposure science and the exposome: an opportunity for coherence in the environmental health sciences [Editorial]. Environ Health Perspect 119:A466-A467; doi:10.1289/ehp.1104387.

Liu P, Hwang JT. 2007. Quick calculation for sample size while controlling false discovery rate with application to microarray analysis. Bioinformatics 23(6):739-746.

Lyons MA, Yang RS, Mayeno AN, Reisfeld B. 2008. Computational toxicology of chloroform: reverse dosimetry using Bayesian inference, Markov chain Monte Carlo simulation, and human biomonitoring data. Environ Health Perspect 116:1040-1046; doi:10.1289/ehp.11079.

Magnus P, Irgens LM, Haug K, Nystad W, Skjaerven R, Stoltenberg C. 2006. Cohort profile: the Norwegian Mother and Child Cohort Study (MoBa). Int J Epidemiol 35(5):1146-1150.

Molitor J, Papathomas M, Jerrett M, Richardson S. 2010. Bayesian profile regression with an application to the National Survey of Children's Health. Biostatistics 11(3):484-498.

National Research Council. 2012. Exposure Science in the 21st Century: A Vision and Strategy. Washington DC:National Academies Press.

Nieuwenhuijsen MJ, Smith R, Golfinopoulos S, Best $N$, Bennett J, Aggazzotti G, et al. 2009. Health impacts of long-term exposure to disinfection by-products in drinking water in Europe: HIWATE. J Water Health 7(2):185-207.

Papathomas M, Molitor J, Richardson S, Riboli E, Vineis P. 2011. Examining the joint effect of multiple risk factors using exposure risk profiles: lung cancer in nonsmokers. Environ Health Perspect 119:84-91; doi:10.1289/ehp.1002118.

Patel CJ, Bhattacharya J, Butte AJ. 2010. An environment-wide association study (EWAS) on type 2 diabetes mellitus. PLoS One 5(5):e10746; doi:10.1371/journal.pone.0010746.

Patel CJ, Chen R, Kodama K, loannidis JP, Butte AJ. 2013. Systematic identification of interaction effects between genome- and environment-wide associations in type 2 diabetes mellitus. Hum Genet 132(5):495-508.

Philippat C, Wolff MS, Calafat AM, Ye X, Bausell R, Meadows M, Stone J, Slama R, Engel SM. 2013. Prenatal exposure to environmental phenols: concentrations in amniotic fluid and variability in urinary concentrations during pregnancy. Environ Health Perspect 121:1225-1231; doi:10.1289/ehp.1206335.

Preau JL Jr, Wong LY, Silva MJ, Needham LL, Calafat AM. 2010. Variability over 1 week in the urinary concentrations of metabolites of diethyl phthalate and di(2-ethylhexyl) phthalate among eight adults: an observational study. Environ Health Perspect 118:1748-1754; doi:10.1289/ehp.1002231.

Rappaport SM. 2011. Implications of the exposome for exposure science. J Expo Sci Environ Epidemiol 21(1):5-9.

Rappaport SM, Smith MT. 2010. Environment and disease risks. Science 330(6003):460-461.

Raven JC, Raven J, Court JH. 1998. Raven's Progressive Matrices und Vocabulary Scales. Frankfurt:Swets \& Zeitlinger B.V.

Rojas-Rueda D, de Nazelle A, Teixido 0, Nieuwenhuijsen MJ. 2012. Replacing car trips by increasing bike and public transport in the greater Barcelona metropolitan area: a health impact assessment study. Environ Int 49:100-109.

Rueda MR, Fan J, McCandliss BD, Halparin JD, Gruber DB, Lercari LP, Posner MI. 2004. Development of attentional networks in childhood. Neuropsychologia 42(8):1029-1040.

Rusiecki JA, Baccarelli A, Bollati V, Tarantini L, Moore LE, Bonefeld-Jorgensen EC. 2008. Global DNA hypomethylation is associated with high serum-persistent organic pollutants in Greenlandic Inuit. Environ Health Perspect 116:1547-1552; doi:10.1289/ehp.11338.

Saito R, Smoot ME, Ono K, Ruscheinski J, Wang PL, Lotia S, et al. 2012. A travel guide to Cytoscape plugins. Nat Methods 9(11):1069-1076.

Seckmeyer G, Klingebiel M, Riechelmann S, Lohse I, McKenzie RL, Liley JB, et al. 2011. A critical assessment of two types of personal UV dosimeters. Photochem Photobiol 88:215-222.

Shi M, Weinberg CR. 2011. How much are we missing in SNPby-SNP analyses of genome-wide association studies? Epidemiology 22(6):845-847.

Slama R, Werwatz A. 2005. Controlling for continuous confounding factors: non- and semiparametric approaches. Rev Epidemiol Sante Publique 53(spec no 2):2S65-S80.

Sobus JR, Tan YM, Pleil JD, Sheldon LS. 2011. A biomonitoring framework to support exposure and risk assessments. Sci Total Environ 409(22):4875-4884. 
Vrijheid et al.

Trasande L, Cronk C, Durkin M, Weiss M, Schoeller DA, Gall EA et al. 2009. Environment and obesity in the National Children's Study. Environ Health Perspect 117:159-166; doi:10.1289/ehp.11839.

Ulaszewska MM, Ciffroy P, Tahraoui F, Zeman FA, Capri E, Brochot C. 2012. Interpreting PCB levels in breast milk using a physiologically based pharmacokinetic model to reconstruct the dynamic exposure of Italian women. J Expo Sci Environ Epidemiol 22(6):601-609.

Van den Bergh BR. 2011. Developmental programming of early brain and behaviour development and menta health: a conceptual framework. Dev Med Child Neurol 53(suppl 4):19-23.
Vrijheid M, Casas M, Bergstrom A, Carmichael A, Cordier S, Eggesbo M, et al. 2012. European birth cohorts for environmental health research. Environ Health Perspect 120:29-37; doi:10.1289/ehp.1103823.

Vuontela V, Steenari M-R, Carlson S, Koivisto J, Fjällberg M, Aronen ET. 2003. Audiospatial and visuospatial working memory in 6-13 year old school children. Learn Mem 10(1):74-81.

Wigle DT, Arbuckle TE, Turner MC, Berube A, Yang 0, Liu S, et al. 2008. Epidemiologic evidence of relationships between reproductive and child health outcomes and environmental chemical contaminants. J Toxicol Environ Health B Crit Rev 11(5-6):373-517.
Wild CP. 2005. Complementing the genome with an "exposome": the outstanding challenge of environmental exposure measurement in molecular epidemiology. Cancer Epidemiol Biomarkers Prev 14(8):1847-1850.

Wild CP. 2012. The exposome: from concept to utility. Int J Epidemiol 41(1):24-32.

Wright J, Small N, Raynor P, Tuffnell D, Bhopal R, Cameron N, et al. 2013. Cohort profile: The Born in Bradford multiethnic family cohort study. Int J Epidemiol 42(4):978-991. 